\title{
Correction to: Distribution Line Pole Detection and Counting Based on YOLO Using UAV Inspection Line Video
}

\author{
Binghuang Chen ${ }^{1,2,3}$ (D) Xiren Miao ${ }^{1}$
}

Published online: 4 September 2019

(c) The Korean Institute of Electrical Engineers 2019

\section{Correction to: Journal of Electrical Engineering \& Technology https://doi.org/10.1007/s42835-019-00230-w}

The article "Distribution Line Pole Detection and Counting Based on YOLO Using UAV Inspection Line Video“, written by Binghuang Chen and Xiren Miao was originally published electronically on the publisher's internet portal (currently SpringerLink on 11 July 2019 with open access.
With the author(s)' decision to step back from Open Choice, the copyright of the article changed on August 2019 to () The Korean Institute of Electrical Engineers 2019 and the article is forthwith distributed under the terms of copyright.

Publisher's Note Springer Nature remains neutral with regard to jurisdictional claims in published maps and institutional affiliations.

The original article can be found online at https://doi.org/10.1007/ s42835-019-00230-w.

Binghuang Chen

chenbh@ jut.edu.cn

Xiren Miao

miaoxr@163.com

1 College of Electrical Engineering and Automation, Fuzhou University, Fuzhou, China

2 School of Information Science and Engineering, Fujian University of Technology, Fuzhou, China

3 Fujian Key Laboratory of Automotive Electronics and Electric Drive, Fuzhou, China 